\title{
Analisis Video Comments To Like Ratio Tiktok Pada 5 Brand Mobil Terbaik Dunia
}

\author{
I Dewa Gede Dharma Wira Widnyana \\ Dewadharma79@gmail.com
}

\begin{abstract}
TikTok is a social media application launched by a Chinese company. TikTok allows users to create 15 -second videos accompanied by music, filters, and several other creative features. In Indonesia, there are 30.7 million active users, making Indonesia the country with the largest TikTok users in the world. The large number of active TikTok users in Indonesia can certainly provide an opportunity for brands to make the TikTok platform a social media marketing platform. There are 5 Local Skin Care Brands in Indonesia that use TikTok as a marketing platform, namely: Somethinc, N'Pure, Avoskin, White Lab and Ms Glow. The purpose of this study is to calculate the credibility of the account performance of TikTok 5 Local Skin Care Brands in Indonesia. The method used for this research is quantitative exploratory method. The results of this study indicate that SomeThinc skin care gets the first rank and has good account performance credibility.
\end{abstract}

\begin{abstract}
ABSTRAK
TikTok merupakan aplikasi sosial media yang diluncurkan oleh perusahaan asal Tiongkok. TikTok memungkinkan penggunanya membuat video berdurasi 15 detik yang disertai dengan musik, filter, dan beberapa fitur kreatif lainnya. Di Indonesia terdapat 30,7 juta pengguna yang aktif sehingga menjadikan Indonesia sebagai negara dengan pengguna TikTok terbesar di dunia. Maraknya jumlah pengguna TikTok yang aktif di Indonesia tentu dapat memberikan peluang bagi brand untuk menjadikan platform TikTok sebagai platform social media marketing. Adapun 5 Brand Mobil Dunia yang memanfaatkan TikTok sebagai platform marketing, yaitu :Ferrari,Lamboghini,Mercedes-Benz,Daihatsu,Buggati. Tujuan dari penelitian ini yaitu untuk menghitung kredibilitas dari performa akun TikTok 5 Brand Mobil Terbaik Dunia . Metode yang digunakan untuk penelitian ini yaitu metode eksploratif kuantitatif. Hasil dari penelitian ini menunjukan bahwa mobil Mercedes-benz mendapatkan peringkat pertama dan memiliki kredibilitas performa akun yang baik.
\end{abstract}

Keyword : Credibility Account TikTok ; Social Media Marketing ; Social Media TikTok ; Video Comments To Like Ratio;Brand mobil Di dunia. 


\section{Pendahuluan}

Media sosial adalah sebuah media online, pengguna dapat dengan mudah berpartisipasi, berbagi dan menciptakan isi meliputi blog, jejaring sosial, wiki, forum dan dunia virtual. Keberadaan media sosial sebagai jejaring sosial di dunia virtual merupakan salah satu jenis media siber. Blog, jejaring sosial dan wiki merupakan bentuk media sosial yang paling umum digunakan oleh orang di seluruh dunia. Media sosial juga bisa dimiliki oleh semua orang. Adanya media sosial, hanya butuh hitungan detik untuk menyampaikan pesan kepada seseorang yang ingin dituju. Media sosial merupakan alat dimana kita bisa menulis pesan, merekam video dan mengirimnya secara personal maupun diunggah secara publik dan penerima atau publik pun bisa menerimanya dengan cepat dalam hitungan detik saja. Media sosial bisa mempertemukan orang dari berbeda negara, komunikasi yang dilakukan tanpa perlu bertemu secara langsung, mempertemukan para alumni sekolah yang sudah berpisah kota, sampai meminta bantuan pada publik untuk menemukan orang yang tidak pernah dijumpai lagi. (Agbasiere V, 2018). (Ririn Arifah 2014)

Salah satu media sosial yang sedang ramai digunakan oleh hampir kebanyakan orang saat ini adalah TikTok. Media Sosial TikTok dengan mudah diakses oleh hampir kebanyakan kaum milenial, hanya dengan mengunduh dan membuat akun, mereka sudah bisa memiliki akun di TikTok. Di tengah perkembangan jaman yang sudah modern ini, media sosial sepertinya telah menjadi kebutuhan primer di masyarakat, berdampingan dengan kebutuhan pokok seperti makan dan bekerja maupun belajar. (Tiara Dewi, Muhammad Amir Masruhim 2016)

Pada aplikasi Tik Tok, penggunanya dapat membuat video yang berdurasi 15 detik dan 60 detik serta bisa memberikan special effects dan music yang unik dan beragam sehingga penggunanya bias menggunakan fitur-fitur tersebut dengan membuat gaya tarian sendiri sesuai dengan musiknya, hal itu mendorong penggunanya untuk menjadi seorang content creator, banyak juga music yang tadinya tidak terkenal menjadi terkenal karena dipakai sebagai background music di video-video yang di unggah di Tik Tok. Video-video yang dibuat oleh penggunanya juga bisa dibagikan lagi ke aplikasi lain seperti Instagram.Unggahan-unggahan yang terdapat di Tik Tok sangat berbeda dari unggahan-unggahan yang terdapat di media sosial lainnya. Mulai dari unggahan yang berisi curhatan hati seseorang, kata-kata motivasi, terdapat juga unggahan yang megedukasi mengenai pengetahuan umum dan kehidupan seharihari. Para content creator juga banyak di endorse oleh online shop untuk mengunggah produk mereka di akun content creator tersebut("Tiktok" 2020)(Akhir, Ii, and Otomotif, n.d.)

TikTok memungkinkan penggunanya membuat video berdurasi 15 detik yang disertai dengan musik, filter, dan beberapa fitur kreatif lainnya. Di Indonesia terdapat 30,7 juta pengguna yang aktif sehingga menjadikan Indonesia sebagai negara dengan pengguna TikTok terbesar di dunia. Maraknya jumlah pengguna TikTok yang aktif di Indonesia tentu dapat memberikan peluang bagi brand untuk menjadikan platform TikTok sebagai platform social media marketing. Adapun 5 Brand Mobil Dunia yang memanfaatkan TikTok sebagai platform marketing, yaitu :Ferrari,Lamboghini,MercedesBenz,Daihatsu,Buggati.(5 Brand Mobil Terbaik Di Dunia, n.d.) 


\section{Tinjauan pustaka}

Adanya media sosial, hanya butuh hitungan detik untuk menyampaikan pesan kepada seseorang yang ingin dituju. Media sosial merupakan alat dimana kita bisa menulis pesan, merekam video dan mengirimnya secara personal maupun diunggah secara publik dan penerima atau publik pun bisa menerimanya dengan cepat dalam hitungan detik saja. Media sosial bisa mempertemukan orang dari berbeda negara, komunikasi yang dilakukan tanpa perlu bertemu secara langsung, mempertemukan para alumni sekolah yang sudah berpisah kota, sampai meminta 3 bantuan pada publik untuk menemukan orang yang tidak pernah dijumpai lagi

Salah satu media sosial yang sedang ramai digunakan oleh hampir kebanyakan orang saat ini adalah TikTok. Media Sosial TikTok dengan mudah diakses oleh hampir kebanyakan kaum milenial, hanya dengan mengunduh dan membuat akun, mereka sudah bisa memiliki akun di TikTok. Di tengah perkembangan jaman yang sudah modern ini, media sosial sepertinya telah menjadi kebutuhan primer di masyarakat, berdampingan dengan kebutuhan pokok seperti makan dan bekerja maupun belajar.("Tiktok" 2020)(Saifuddin Azwar 2007)

Tik Tok merupakan aplikasi Sosial Media yang menjadi budaya populer di Indonesia mulai awal tahun 2020 ini. Tik Tok sendiri dalam pelafalan bahasa cina di sebut Douyin yang merupakan aplikasi video musik yang pada awalnya digunakan untuk hiburan lipsync lagu oleh penggunanya, aplikasi ini dari berasal dari negeri Tiongkok yang diciptakan oleh ByteDance tahun 2016 Pada tahun 2017 aplikasi Tik Tok mulai masuk ke Indonesia, namun pada saat itu aplikasi ini dianggap "norak" dan ditolak oleh masyarakat Indonesia dan pada puncaknya pada Juli 2018 dilakukan pemblokiran aplikasi TikTok di Indonesia oleh Kementrian Komunikasi dan Informatika. ("Tiktok" 2020)(Carmudi.com, n.d.)

Pada aplikasi Tik Tok, penggunanya dapat membuat video yang berdurasi 15 detik dan 60 detik serta bisa memberikan special effects dan music yang unik dan beragam sehingga penggunanya bias menggunakan fitur-fitur tersebut dengan membuat gaya tarian sendiri sesuai dengan musiknya, hal itu mendorong penggunanya untuk menjadi seorang content creator. Musik-musik yang tersedia juga merupakan musik dari artis terkenal, banyak juga music yang tadinya tidak terkenal menjadi terkenal karena dipakai sebagai background music di video-video yang di unggah di Tik Tok. Video-video yang dibuat oleh penggunanya juga bisa dibagikan lagi ke aplikasi lain seperti Instagram("Tiktok" 2020)(Tempo.com, n.d.) 


\section{METODE PENELITIAN}

Penelitian ini menggunakan metode eksploratif kuantitatif untuk mengetahui kredibilitas dari performa akun TikTok 5 Brand Mobil Terbaik Di Dunia.Penelitian eksploratif merupakan penelitian terhadap permasalahan yang belum pernah dijejaki, belum pernah diteliti orang lain sehingga walaupun dalam "kegelapan" peneliti eksplorasi tetap berusaha menemukan permasalahan yang sedang atau akan di teliti tersebut.

Tujuan dari penelitian ini yaitu mengetahui nilai kredibillitas dari performa akun TikTok 5 Brand Mobil Terbaik Di Dunia(Otomotif.com, n.d.). Ada beberapa langkah yang harus dilakukan dalam penelitian ini, sehingga mampu menemukan peringkat pertama akun TikTok Brand Mobil Terbaik Di Dunia yang memiliki performa terbaik. Langkah-langkah yang dilakukan pada penelitian ini, diantaranya yaitu;

\section{Melakukan Eksplorasi Pada Website Untuk Menentukan Objek yang Akan Dianalisa.}

Eksplorasi ini dilakukan pada beberapa halaman website yang menyediakan informasi mengenai objek yang akan di teliti. Setelah ekslorasi selesai dilakukan, sehingga ditemukan nama-nama brand Brand Mobil Terbaik Di Dunia yang akan dijadikan objek analisa. Setelah melakukan eksplorasi pada halaman website, maka langkah selanjutnya yaitu mencari nama akun TikTok dari masing-masing Brand Mobil Terbaik Di Dunia. Pastikan semua brand memiliki akun pada aplikasi sosial media TikTok.

\section{Menghitung Nilai Rata-Rata Variable Dari 5 Brand Skin Care Lokal Terlaris di Indonesia.}

Pada langkah ini, peneliti menghitung nilai variable video comments dan variable video views.Secara teoritis variabel adalah atribut seseorang, atau obyek yang mempunyai "variasi" antara satu orang dengan yang lain atau satu obyek dengan obyek lainnya (Saifuddin Azwar 2007). Untuk menghitung nilai rata-rata dari variabel Video Comments To Like yaitu dengan cara mengambil minimal 10 postingan kemudian di hitung sehingga menemukan nilai rata-rata dari masing-masing variabel. 


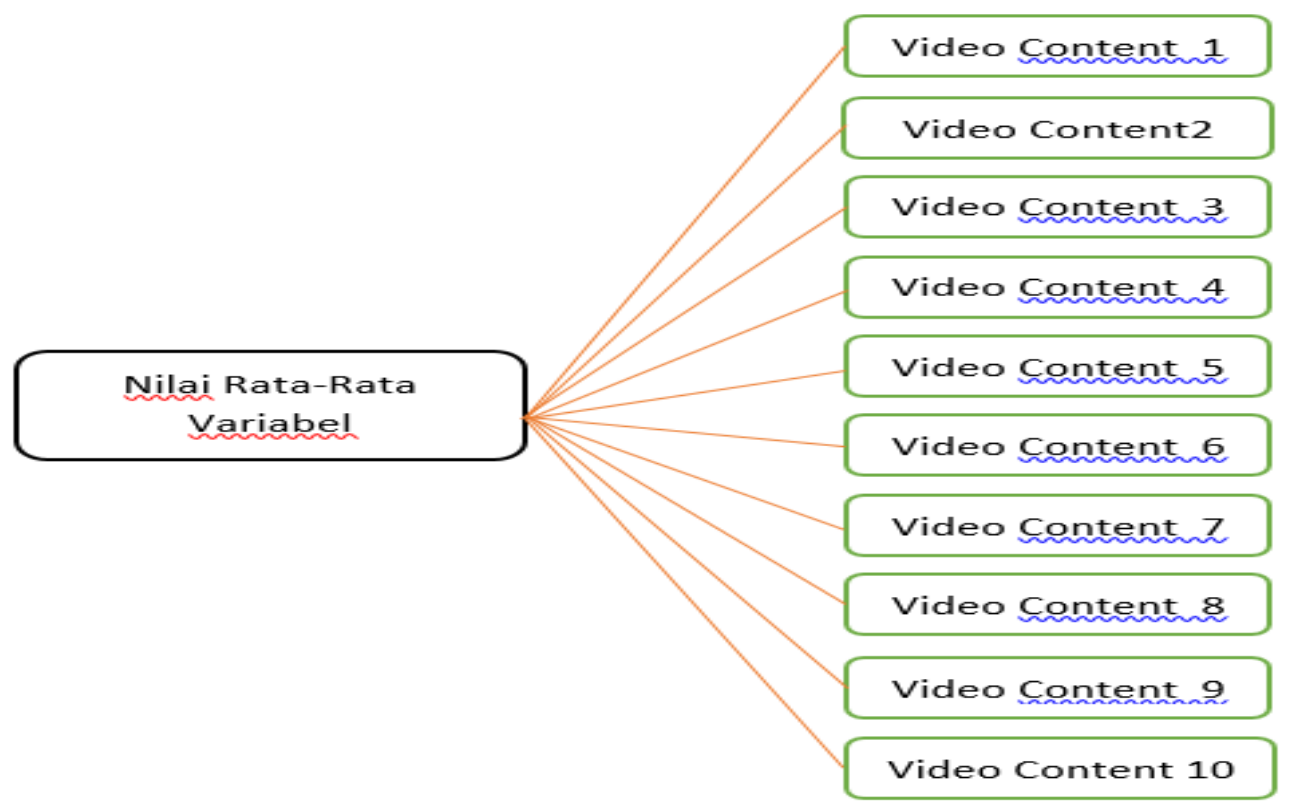

\section{Menghitung Nilai Kredibilitas Rasio}

Untuk menghitung nilai kredibilitas dari Video Comments To Like Ratio, peneliti menggunakan cara membagi nilai variabel pertama dengan nilai variabel kedua. Jika video share memiliki nilai 2.000 dan followers memiliki nilai 8.000 , maka cara menghitungnya yaitu $2.000: 8.000=0,25$. Dengan begitu nilai dari Video Comments To Like adalah 0,25

\section{Menentukan Peringkat Pada Akun TikTok}

Pada langkah terakhir yang dilakukan pada penelitian ini yaitu menentukan peringkat pada masing-masing rasio yang ada. Pada penentuan peringkat perlu melihat karakteristik dari rasio yang di teliti. Jika karakteristik rasio merupakan rendah, maka objek yang memiliki nilai terendah akan mendapatkan angka 5 dan objek yang memiliki nilai tertinggi akan mendapatkan angka 1 . Namun jika rasio memiliki karakteritik tinggi maka objek yang mendapatkan nilai tinggi akan mendapatkan angka 5 dan objek yang mendapatkan nilai terendah akan mendapatkan angka 1. Setelah mendapatkan hasil kredibilitas ratio maka dapat disimpulkan objek yang mana mendapatkan peringkat 1 sampai dengan peringkat 5 . 


\section{Hasil dan pembahasan}

1.Lamborghini

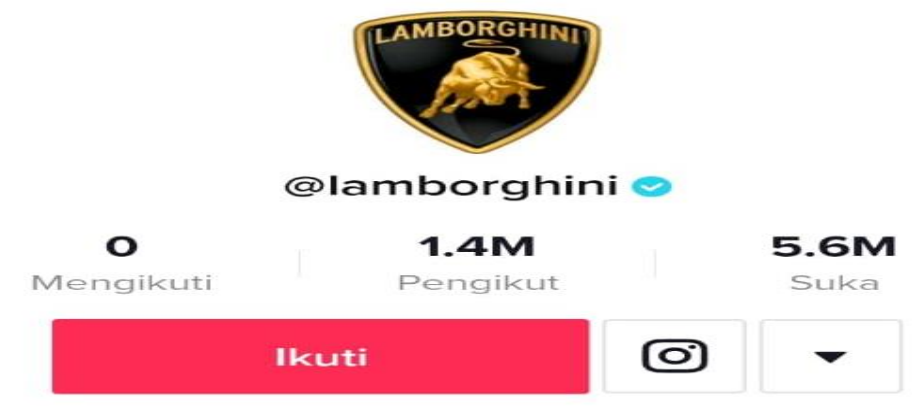

Welcome to the official account of Automobili Lamborghini

(5) wnwlamborghini.com

$\square$ Email

Sumber : $\underline{\text { https://vt.tiktok.com/ZSeYd8g2m/ }}$

2.Mercedes-Benz

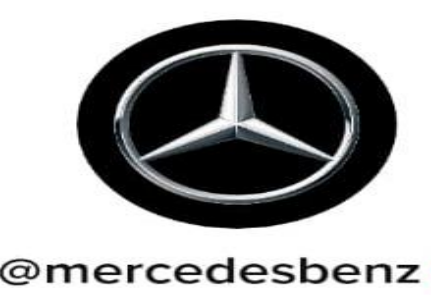

@mercedesbenz

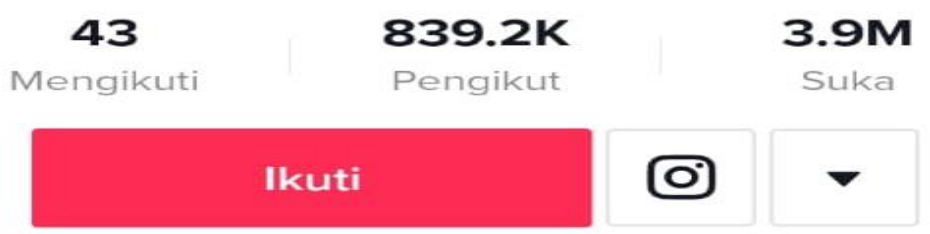

Welcome to the official Mercedes-Benz TikTok channel! $\mathfrak{F}$ http://mb4.me/provider_privacy

Sumber : https://vt.tiktok.com/ZSeYdAD2M/ 


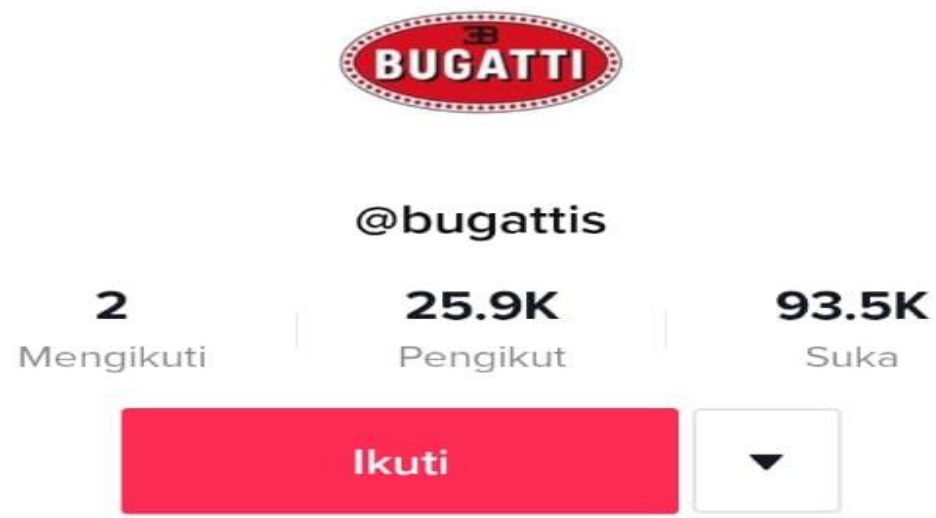

"If comparable, it is no longer Bugatti."

Sumber : https://vt.tiktok.com/ZSeYdMBMU/

4.Daihatsu

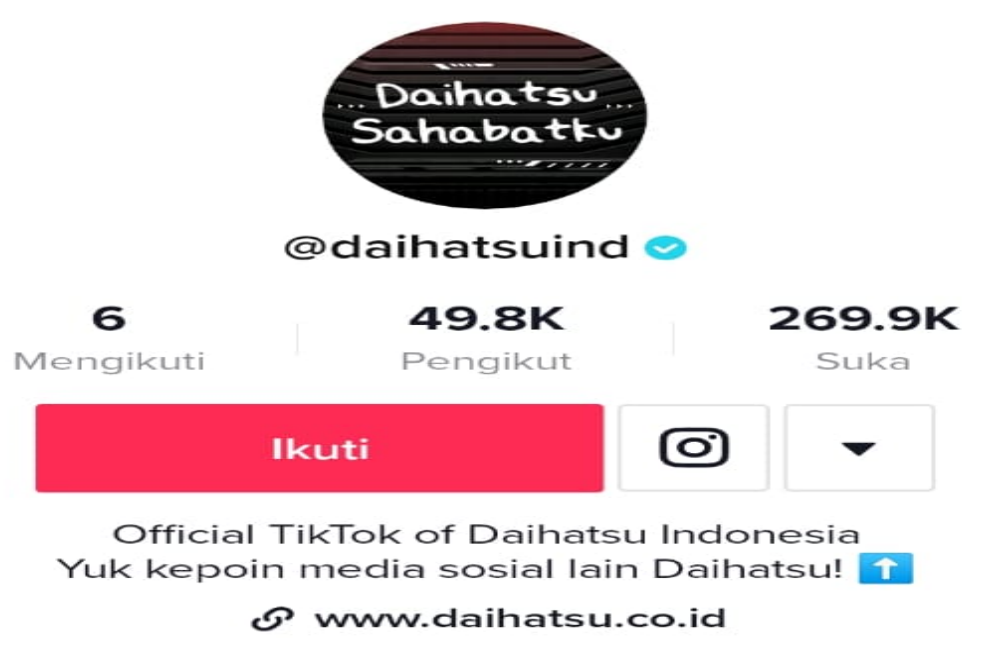

Sumber : https://vt.tiktok.com/ZSeYd2h4S/ 


\section{Ferrari}
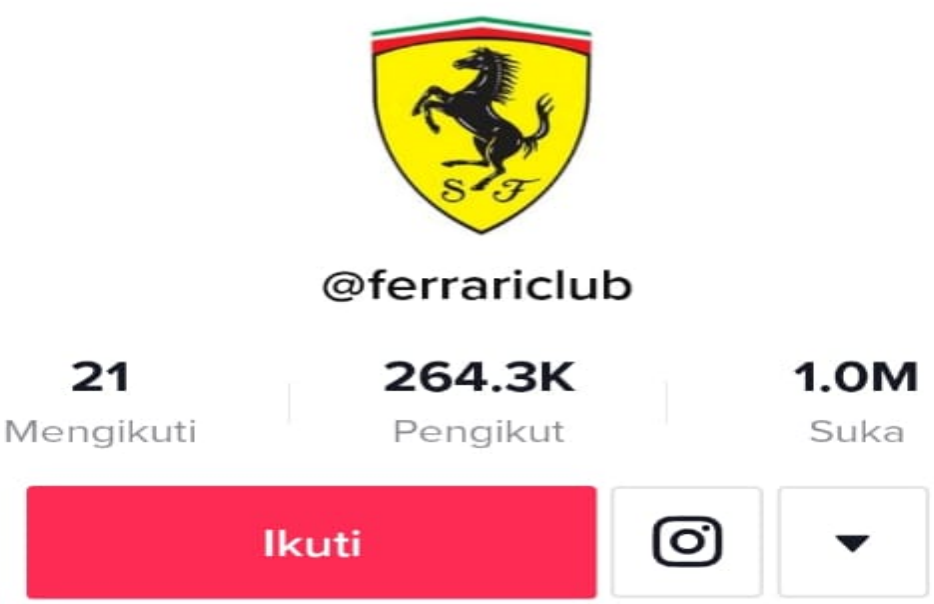

Ferrari Club Worldwide

No Affiliation with Ferrari

Best Ferrari Feed

Sumber : $\underline{\text { https://vt.tiktok.com/ZSeYdU3wt/ }}$

Dari kelima akun TikTok Top 5 Brand Mobil Terbaik Di Dunia, peneliti menemukan nilai dari masingmasing variabel yang ada untuk menghitung rasio Video.

Video Comments To Like dari setiap akun. Pada akun TikTok terdapat 7 variabel, diantaranya yaitu:

1. Likes

2. Followers

3. Following

4. Video Likes

5. Video Comments

6. Video Share

7. Video Views

Dari ketujuh variabel tersebut peneliti hanya fokus untuk menemukan hasil dari 2 variabel, yaitu:

1. Video share

2. Video View

Dari kedua variabel tersebut kemudian dianalisa sehingga menemukan nilai rata-rata dari variabel Video Comments To Like Ratio. Untuk menghitung nilai rata-rata dari Video Comments To Like Ratio yaitu dengan cara mengambil minimal 10 postingan kemudian di hitung sehingga menemukan nilai rata-rata 
dari masing-masing variabel. Berikut merupakan tabel nilai rata-rata dari masing-masing brand fashion termahal di dunia, yaitu

Tabel 1 Analisa rata rata nilai variabel Video Comments To Like Ratio Tiktok Pada akun Brand Mobil Ferarri

\begin{tabular}{|c|c|r|}
\hline \multicolumn{3}{|c|}{ Ferrari } \\
\hline No & Comments & \multicolumn{1}{|c|}{ Like } \\
\hline $\mathbf{1}$ & 132 & 5515 \\
\hline $\mathbf{2}$ & 75 & 5149 \\
\hline $\mathbf{3}$ & 75 & 5562 \\
\hline $\mathbf{4}$ & 32 & 2679 \\
\hline $\mathbf{5}$ & 19 & 2055 \\
\hline $\mathbf{6}$ & 57 & 2788 \\
\hline $\mathbf{7}$ & 27 & 1554 \\
\hline $\mathbf{8}$ & 62 & 2819 \\
\hline $\mathbf{9}$ & 22 & 2011 \\
\hline $\mathbf{1 0}$ & 399 & 19.100 \\
\hline Total & $\mathbf{9 0}$ & $\mathbf{4 9 . 2 3 2}$ \\
\hline
\end{tabular}

Tabel 2 Analisa rata rata nilai variabel Video Comments To Like Ratio Tiktok Pada akun Brand Mobil Mercedes-Benz

\begin{tabular}{|c|c|r|}
\hline \multicolumn{3}{|c|}{ Mercedes-Benz } \\
\hline No & Comments & \multicolumn{1}{c|}{ Like } \\
\hline $\mathbf{1}$ & 19 & 543 \\
\hline $\mathbf{2}$ & 254 & 6992 \\
\hline $\mathbf{3}$ & 27 & 1086 \\
\hline $\mathbf{4}$ & 40 & 1085 \\
\hline $\mathbf{5}$ & 47 & 2478 \\
\hline $\mathbf{6}$ & 111 & 3446 \\
\hline $\mathbf{7}$ & 106 & 3130 \\
\hline $\mathbf{8}$ & 87 & 5519 \\
\hline $\mathbf{9}$ & 340 & 11.900 \\
\hline $\mathbf{1 0}$ & 153 & 3794 \\
\hline Total & $\mathbf{1 1 8 , 4}$ & $\mathbf{3 9 . 9 7 3}$ \\
\hline
\end{tabular}


Tabel 3 Analisa rata rata nilai variabel Video Comments To Like Ratio Tiktok Pada akun Brand Mobil Bugatti

\begin{tabular}{|c|c|r|}
\hline \multicolumn{3}{|c|}{ BUGATTI } \\
\hline No & Comments & Like \\
\hline $\mathbf{1}$ & 38 & 1744 \\
\hline $\mathbf{2}$ & 26 & 1868 \\
\hline $\mathbf{3}$ & 34 & 1070 \\
\hline $\mathbf{4}$ & 91 & 7862 \\
\hline $\mathbf{5}$ & 38 & 989 \\
\hline $\mathbf{6}$ & 20 & 900 \\
\hline $\mathbf{7}$ & 5 & 878 \\
\hline $\mathbf{8}$ & 72 & 1935 \\
\hline $\mathbf{9}$ & 39 & 807 \\
\hline $\mathbf{1 0}$ & 25 & 840 \\
\hline Total & $\mathbf{3 8 , 8}$ & $\mathbf{1 8 . 8 9 3}$ \\
\hline
\end{tabular}

Tabel 4 Analisa rata rata nilai variabel Video Comments To Like Ratio Tiktok Pada akun Brand Mobil Daihatsu

\begin{tabular}{|c|c|r|}
\hline \multicolumn{3}{|c|}{ Daihatsu } \\
\hline No & Comments & Like \\
\hline $\mathbf{1}$ & 2 & 63 \\
\hline $\mathbf{2}$ & 2 & 243 \\
\hline $\mathbf{3}$ & 111 & 1 \\
\hline $\mathbf{4}$ & 23 & 3335 \\
\hline $\mathbf{5}$ & 3 & 55 \\
\hline $\mathbf{6}$ & 41 & 9564 \\
\hline $\mathbf{7}$ & 10 & 383 \\
\hline $\mathbf{8}$ & 1 & 220 \\
\hline $\mathbf{9}$ & 489 & 55.000 \\
\hline $\mathbf{1 0}$ & 384 & 46.600 \\
\hline Total & 106,6 & $\mathbf{1 1 5 . 4 6 4}$ \\
\hline & &
\end{tabular}


Tabel 5 Analisa rata rata nilai variabel Video Comments To Like Ratio Tiktok Pada akun Brand Mobil Lamborghini

\begin{tabular}{|c|c|r|}
\hline \multicolumn{3}{|c|}{ LAMBORGHINI } \\
\hline No & Comments & \multicolumn{1}{c|}{ Like } \\
\hline $\mathbf{1}$ & 130 & 16.200 \\
\hline $\mathbf{2}$ & 1011 & 160.300 \\
\hline $\mathbf{3}$ & 2016 & 241.700 \\
\hline $\mathbf{4}$ & 269 & 20.200 \\
\hline $\mathbf{5}$ & 231 & 16.900 \\
\hline $\mathbf{6}$ & 339 & 50.400 \\
\hline $\mathbf{7}$ & 251 & 40.800 \\
\hline $\mathbf{8}$ & 561 & 40.300 \\
\hline $\mathbf{9}$ & 6502 & 415.300 \\
\hline $\mathbf{1 0}$ & 2207 & 132.300 \\
\hline Total & $\mathbf{1 3 5 1 , 7}$ & $\mathbf{1 . 1 3 4 . 4 0 0}$ \\
\hline
\end{tabular}

Tabel 6.nilai masing masing variable

\begin{tabular}{|l|r|}
\hline \multicolumn{2}{|c|}{ Total Like } \\
\hline Ferrari & 49.232 \\
\hline Mercedes-Benz & 39.973 \\
\hline Bugatti & 18893 \\
\hline Lamborghini & 1.134 .400 \\
\hline Daihatsu & 115.464 \\
\hline
\end{tabular}

\begin{tabular}{|l|c|}
\hline \multicolumn{2}{|l|}{ Rata-Rata Comments } \\
\hline Ferrari & 90 \\
\hline Mercedes-Benz & 118,4 \\
\hline Bugatti & 38,8 \\
\hline Lamborghini & 1351,7 \\
\hline Daihatsu & 106,6 \\
\hline
\end{tabular}


Tabel 7.Hasil perhitungan Rasio Akun tiktok dan Nilai rasio

\begin{tabular}{|l|c|r|r|r|c}
\hline \multicolumn{7}{|c}{ Ratio Video Comments To Likes } \\
\hline \multicolumn{1}{|c|}{ Nama } & Rata-Rata & \multicolumn{1}{c}{ Likes } & \multicolumn{1}{c}{ Total } & Karakteristik & Peringkat \\
\hline Ferrari & 90 & 49.232 & 0,001828079 & Tinggi & 3 \\
\hline Mercedes-Benz & 118,4 & 39.973 & 0,002961999 & Tinggi & 1 \\
\hline Bugatti & 38,8 & 18.893 & 0,002053671 & Tinggi & 2 \\
\hline Lamborghini & 1351,7 & 1.134 .400 & 0,001191555 & Tinggi & 4 \\
\hline Daihatsu & 106,6 & 115.464 & 0,000923231 & Tinggi & 5 \\
\hline
\end{tabular}

Kesimpulan yang didapat dari Video Comments To Like Ratio adalah:

\begin{tabular}{|l|l|l|}
\hline Pertama & Mercedes-Benz \\
\hline Kedua & Bugatti \\
\hline Ketiga & Ferrari \\
\hline Keempat & Lamborghini \\
\hline Kelima & Daihatsu \\
\hline
\end{tabular}




\section{Daftar Pustaka}

5 Brand Mobil Terbaik Di Dunia. n.d. "5 Brand Mobil Terbaik Di Dunia."

https://www.idntimes.com/automotive/car/dwi-agustiar/daftar-ferrari-mobil-termahal-di-dunia-hjk/5.

Akhir, Tugas, B A B li, and Industri Otomotif. n.d. "Henry Ford," 12-31.

Carmudi.com. n.d. "Https://Www.Carmudi.Co.Id/Mobilbaru/Merek/."

Otomotif.com. n.d. "Https://Www.Oto.Com/Mobil-Baru/Brosur."

Ririn Arifah. 2014. "Mobil," 634. https://hsgm.saglik.gov.tr/depo/birimler/saglikli-beslenme-hareketlihayat-db/Yayinlar/kitaplar/diger-kitaplar/TBSA-Beslenme-Yayini.pdf.

Saifuddin Azwar. 2007. "Metodologi Penelitian," no. i: 16-28.

Tempo.com, Otomotif. n.d. “Https://Otomotif.Tempo.Co/Read/1473226/10-Merek-Mobil-Terlaris-PadaMei-2021-Toyota-Teratas."

Tiara Dewi, Muhammad Amir Masruhim, Riski Sulistiarini. 2016. “済無No Title No Title No Title.” Laboratorium Penelitian Dan Pengembangan FARMAKA TROPIS Fakultas Farmasi Universitas Mualawarman, Samarinda, Kalimantan Timur, no. April: 5-24.

“Tiktok." 2020, 1-10. 